\title{
Predefined Project Scope Changes AND ITS CAUSES FOR PROJECT SUCCESS
}

\author{
Theyab Althiyabi and Rizwan Qureshi
}

\author{
Department of Information Technology, Faculty of Computing and \\ Information Technology, King Abdul-Aziz University, Jeddah 80213, Saudi Arabia
}

\begin{abstract}
In project management, the project scope is the base of significant project planning processes such as estimating the cost, schedule and building work breakdown structure. Poor project scope definition directly affects project cost and schedule. Accordingly, dealing with unrealistic scope definition of cost and schedule may lead to failing a project. Besides, changes in project scope have a negative and positive impact on project success. This paper aims to predefine the potential scope changes to keep the project scope on track and identify any weakness in scope definition at the early stages of a project. Enhancing project scope quality has a massive impact on the success of a project and it adds more control over project scope. A method is proposed to improve the quality of project scope and increase the efficiency of controlling scope changes. The proposed method will help to avoid scope creeping by defining a clear statement of work, increase the learning opportunities of the development team to optimize its processes, reducing the communication gap between the clients and development team and screen adjustments of new tasks. The proposed method is validated using a survey and the results are found encouraging.
\end{abstract}

\section{KEYWORDS}

Change Management, Project Scope Changes, Project Management, Scoop Creep, Survey Validation.

\section{INTRODUCTION}

Project management paradigm is application of knowledge, skills and tools to cope the needs and deeds of stakeholders from a project [1]. One of the most significant processes of the project management is the project scope process. The project scope is defined as a statement by writing the context, main inputs and outputs and main functions of the system to be developed. Project scope defines all tasks, activities, resources, timelines, decisions, and project boundaries that must be done to meet project goals and deliverables. The project scope statement (PSS) is prepared for the customer to illustrate the purpose of developing the project and plan of all activities needed to accomplish the project. The PSS warrants that all stakeholders are benefited to understand the project.

There is a solid relationship between project scope, schedule, and cost. Based on this fact, project scope definition has a critical impact on the success of a software project. Project scope must be well defined before estimating the project schedule and cost. Well-defined project scope contributes to deliver a successful project that meets the organization's objectives and project goals. The possibility of project scope changes may occur during the project execution phase that leads to exceeding planned cost and schedule impact on the success of a project [2].

This research aims to investigate the causes of poorly defined scope and propose a solution to overcome the respective problems. The proposed method is classifying the scope changes into two main categories: planned and unplanned (Scope Creep). The proposed method provides an 
International Journal of Software Engineering \& Applications (IJSEA), Vol.12, No.2/3, May 2021

efficient procedure of discovering and dealing with scope changes that may occur on the project scope encompassing the planning and executing phases. In addition, it may provide more control of tracking scope creep or unplanned changes. The proposed method may contribute to increases the awareness of negative changes on the project success and it provides alternative solutions by predefining alternative changes. The purpose of the proposed method is to mitigate the project risks and increase the possibility of meeting project success criteria.

The paper is further arranged as: section II covers the related work. The problem identified in this paper is defined in section III. Section IV illustrated the proposed solution. The proposed solution is validated in section $\mathrm{V}$.

\section{RELATED WORK}

Sharma et al. [1] investigated approaches and techniques that may aid to mitigate the impact of scope creeping and dealing with its consequences. Scope creeping is considered as one of the main causes of project delay, cost overrun and may lead to project failure. A model is proposed that contains tools and techniques to control and address key issues and root causes of scope creeping. The number of experts involved in the validation process (focus group) is not sufficient to achieve accurate or valid results. Moreover, there is a need to conduct further testing of the proposed model on industrial projects to generalize the results.

Scope, cost, and time are the main factors that can cause a software project to be successful or fail [2]. This study is conducted to provide the negative effect of poor scope management and unrealistic expectations enforcing unhealthy changes on project success. However, defining the project schedule needs to be more specific. There is further investigation required to identify critical factors of scope creeping.

Komal et al. [3] proved that inability to manage scope creep leads to project failure, more than $80 \%$ of software project failed as the result of poor controlling of scope creep. Nevertheless, numerous organizations are not aware of the serious parts of scope creep, hence conducted study contributes to decrease the chances of projects failure by identifying and analysing the critical factors that are responsible for scope creep proved by using a systematic review based on 29 selected paper. However, there is a need to observe the impact of identified factors on real projects due to the absence of observation proof available in the reviewed literature.

An improvement of Earned Scope Management (ESM) strategy for measuring and checking project performance is a technique proposed by Valdés-Souto [4] by enabling the use of the exertion and the people as a resource in the project. Project scope is considered as one of the critical factors that affect project success, although, there is a lack of scientific researches being done on scope techniques for monitoring and controlling scope constraints. Therefore, the proposed improvement of ESM contributes to improving project performance, hence prevent project failure. Nonetheless, it is important to integrate ESM with Earned Value Management (EVM) primary factors (cost and schedule) to achieve an accurate result and full status of project performance.

Hassan et al. [5] presented a method to evaluate the completeness of scope definition. The welldefined scope contributes to project success. There are several tools used for measuring and verifying product scope definition, and control scope changes. Besides, there are no specific tools used to gauge completeness and quality of scope definition. Therefore, the proposed method promoted the quality of the completeness of the project scope definition and provided more control of its work. However, the evaluation method was applied on three software projects only which is an insufficient number to obtain a confident result. 
How appropriate methodology and tools of change management positively impact improvement projects for success. A large number of organizations facing challenges on improvement for success and applying changes that must be implemented, numbers methodologies used for problem solving. However, it isn't sufficient to have a huge achievement without a process integrating with the approaches for address the problems for changing.

Xiong et al. [6] conduct a case study to prove that the methodology used in change management change empowers achievement changing from improvement project theoretically through problem solving methodology. Besides the above, the study should expand the relative application in more different organizations to obtain the most satisfying result.

Israeli and Gonen [7] discussed the coherence relation between them. Nowadays organizations consider knowledge management as one of the significant resources, sharing knowledge contributes to project success. On the other hand, not all organizations are aware of how exchanging knowledge management can lead the project to success, hence they are not assimilating a culture of remuneration or invest in sharing knowledge. The proposed study focused on the impact of knowledge management on project success from multiple perspectives. However, it was proved by using online questionnaires, in addition, the number of variables on the study was quite large, therefore increasing the sample may positively support the results.

Dludhlu et al. [8] conducted a study for "Risk Evaluation in Project Management Implementation: The Case of Infrastructural Development Projects". The risk management process is significant in managing project success. One of the most important success keys of the project is to identify the project risks that may arise during the project life cycle. The misalignment between project goals and the organization's strategic goals, changes in management personnel, and lack of technical support are a risk that impacts negatively on the project achievements. The study proves that managing risks properly through the project life cycle contributes to mitigating risks and preventing project failure. There needs to consider the impact of the project scope as a critical factor that may affect mainly project success. The weak scope definition contributes to producing a gap between project objectives and organization strategies. However, ignoring the importance of including the scope impact as an effective factor may affect the project success considered as a limitation in this study.

Battistello et al. [9] submitted four steps framework that applied to the international company. Product Information Management (PIM) is a new type of software and recently is growing in demand to include all business sizes. The study focused on significant points such as identifying the stakeholders, collect the requirements, understanding the working process, and framing the PIM model. There was little information about the PIM in the literature review, and there was no study that focused on the PIM scoping process in depth. Therefore, this study filled that gap by developing a framework to support the PIM. The testing on the proposed framework implemented on a single international company that considers a limitation may negatively impact the accuracy of deliverables and validation.

Pollack [10] discussed two different approaches, project management (PM), and change management (CM) depends on the literature review. The traditional PM focuses on the cost, schedule, and quality, while CM focuses on developing vision, leadership change, ownership, and alignment strategies. Despite the differences between the approaches, the discussion focused on the benefits of involving PM and CM approaches in one integrated model to deliver business objectives effectively. However, isolating PM and CM may cause tension and be less efficient. Therefore, Pollack discussed the storage coherence relation, dependency, and shared aspects between project management and change management. Hence, it is confirmed that the integration 
International Journal of Software Engineering \& Applications (IJSEA), Vol.12, No.2/3, May 2021

of PM and CM effect positively on the project deliverables to keep them under control. However, there is a need to apply the proposed research to an industrial case study to validate.

Table 1. The main limitations of related work.

\begin{tabular}{|c|c|}
\hline Title & Limitations \\
\hline $\begin{array}{l}\text { Approaches and techniques aid to mitigate the } \\
\text { impact of scope creeping [1] }\end{array}$ & $\begin{array}{l}\text { The validation of the model may be affected by } \\
\text { the lack number of expertise participated in the } \\
\text { validation process. } \\
\text { The proposed model is not tested in real projects. }\end{array}$ \\
\hline $\begin{array}{l}\text { Investigating and identifying the critical factors } \\
\text { of scope creep and its influence on project } \\
\text { success [3] }\end{array}$ & $\begin{array}{l}\text { The paper requires more validation on real } \\
\text { projects due to the absence of observation proof } \\
\text { available in the reviewed literature. }\end{array}$ \\
\hline $\begin{array}{l}\text { Improvement of Earned Scope Management } \\
\text { (ESM) strategy for measuring and checking } \\
\text { project performance [4] }\end{array}$ & $\begin{array}{l}\text { There is a need to integrate ESM) Earned Scope } \\
\text { Management with Earned Value } \\
\text { Management (EVM) to obtain accurate result of } \\
\text { project performance. }\end{array}$ \\
\hline $\begin{array}{l}\text { Method to evaluate the completeness of scope } \\
\text { definition [5] }\end{array}$ & $\begin{array}{l}\text { It is difficult to generalize the result of the } \\
\text { proposed method based on the evaluations of } \\
\text { three projects only. }\end{array}$ \\
\hline $\begin{array}{l}\text { A case study to describe how appropriate } \\
\text { methodology and tools of change management } \\
\text { positively impact on improvement projects for } \\
\text { success. [6] }\end{array}$ & $\begin{array}{l}\text { The study should expand the relative application } \\
\text { in more different organizations in order to obtain } \\
\text { the most satisfying result. }\end{array}$ \\
\hline $\begin{array}{l}\text { The coherence relationship between knowledge } \\
\text { management in the organization and project } \\
\text { success [7] }\end{array}$ & $\begin{array}{l}\text { Since online questionnaire was used and the } \\
\text { number of variables is quite large, increasing the } \\
\text { sample will positively support the results. }\end{array}$ \\
\hline $\begin{array}{l}\text { Risk Evaluation in Project Management } \\
\text { Implementation: The Case of Infrastructural } \\
\text { Development Projects [8] }\end{array}$ & $\begin{array}{l}\text { There is a need to include project scope as one } \\
\text { of the important factors in the study as poor } \\
\text { scope definition could also cause an obvious gap } \\
\text { between project goals and organization goals. }\end{array}$ \\
\hline $\begin{array}{l}\text { Scoping a PIM } \text { System: } \\
\text { Framework [9] }\end{array}$ & $\begin{array}{l}\text { The proposed solution is validated on only one } \\
\text { company which is not efficient enough to } \\
\text { support the accuracy and reliability of overall } \\
\text { testing results. }\end{array}$ \\
\hline
\end{tabular}

It is described that the existing literature is evident to narrate that scope creeping is one of the most communal reasons for the failure of software projects [11]. It is also believed in the software community that scope creeping can happen in approximately all software projects resulting to negotiate in quality, extra schedule, more costly and poor customer satisfaction. There are few empirical evidences available to show the relationship between scope creeping and success of software projects. A theoretical framework is proposed to calculate the impact of scope creep on the success or failure of software projects. A systematic literature review (SLR) and interview from experts are used to conclude the results. It is narrated that the scope creep is adversely related with the success of software projects.

EVM estimates the velocity of a project if $15 \%$ of a project is accomplished [12]. It is used to point out the problems in the project with respect to schedule and cost and facilitates a project manager to keep track the economic and schedule progress and measure the variances. Variance is defined as deviation from an actual plan. EVM is continuously applied throughout the lifecycle of a project to measure any variance so that corrective actions can be applied. It estimates cost and schedule performance indicators. Existing studies emphasizes the importance of scope by considering it as a main indicator to estimate the success or failure of a project. EVM does not 
International Journal of Software Engineering \& Applications (IJSEA), Vol.12, No.2/3, May 2021

incorporate scope while estimating the performance indicators of a software project. Changes in scope are normal as per the nature of software projects. It is important to evaluate the effect of changes in scope and plan during the development of a software project. Seventeen distinctive factors are identified to predict the deviations in scope as per the planned project budget.

PM has transformed into highly tactical discipline over the years due to demand of integrated systems, growth of software projects, tight deadlines and market pressure [13]. EVM helps the project managers to measure and track the progress of the projects. The research is conducted to illustrate a method to forecast budget and schedule of the project and choose the suitable plan of action. Control charts and EVM are used together to improve the correctness. A case study is conducted to validate the proposed method. The best action plan is achieved by the assessments of an expert. A mathematical model is needed to amalgamate into the proposed method to avoid the limitation of a human expert to choose the suitable plan of action.

EVM is extensively practiced in software industry to plan, monitor and control the projects due to its effectiveness [14]. Earned schedule, quality management, and risk management are amalgamated into EVM to tackle its flaws and shortcomings to suggest a novel model. The novel model is validated using a case study to check its effectiveness. The results of the case study provide evidence that the proposed model improves the prediction of budget and duration risks better than the EVM. The corrective actions, to avoid risks, are also indicated in the risk register during the development of a project. The proposed model shows clear extensions in schedule and it is very easy to understand the extra schedule.

The main limitations of related work are shown in Table 1.

\section{Problem Definition}

Changes in a project is a must and it cannot be isolated, changes on the projects have a positive and negative impact on the project scope and on overall project status, changes can be small or big. Despite the size of changes and the size of project scope, these changes on project scope can lead to project failure. Komal et al. [3] mentioned that "According to the results of the survey, $92 \%$ of participants claimed that their projects failed due to poor scope management. To emphasize this point, both changes in scope (41\%) and poor estimates $(39 \%)$ were reported". Small changes called scope creep, Komal et al. [3] have defined as "Scope creep refers to the change or growth of project scope or pressure to deliver more than what was approved between different parties". Even though these small changes are dangerous if it occurs during the project as it's not formal and its implemented without planning or assessment for its effect on the project baselines. Komal et al. [3] have also mentioned that "when scope creeps never occurred, the success rate of a project seemed to be $100 \%$." [3]. There is a coherence relation between poor scope management and the number of changes during the project. The study conducted by Adam and Danaparamita [2] proved that the "correlation between unrealistic expectation and changes occur is exist". Besides above an increased number of unhealthy scope changes during the project considered as a risk that causes instability of project status and may need a corrective action that requires additional rework effort under the pressure of time and budget, hence lead the project to be overrun of cost and time, finally project failure.

Contradictorily, all changes in scope are not wrong; numerous changes are healthy that positively impact the success of a project. However, as a project manager if you ignore healthy changes and identify them late may lead to missing the opportunities that contribute to improve project performance and achieve project success and even save the amount of planned time and cost. 


\section{The Proposed Solution}

Figure 1 displays the proposed model to discover the changes in the scope at the initial stages of a software project. Figure 2 shows to manage predefined project scope changes method. Early knowledge of potential project scope changes help the project managers to reduce the amount of scope creep, mitigate the risk, aware of any uncertainty expectations of project scope, detect poor scope definition, early corrective action, avoided rework and prevent over cost \& time, and provide better change control management, predefined changes integrated with change management plan assist the project manager to confidently deal with changes without the pressure of time and work during project executing phase [15-16].

Potential changes may be discovered by using different techniques, a project manager can use expert judgment to evaluate the current scope after finalizing the scope definition, this aids to identify any weakness or uncertainty expectations of project scope which may not meet with project goals and origination objectives, hence provides corrective changes to change project scope before it negatively influences the whole project. In addition, the project manager may use the knowledge of lesson learned register and changelog for similar previous projects to review how scope changes affect project success, this will assist to discover some potential changes on the current scope, using bench market can be a great way to obtain the knowledge of what changes may occur during the executing phase of the project. Furthermore, conducting brainstorming sessions and using what-if analysis contributes to discovering more potential changes.

Predefined scope changing is not limited to the planning phase, unplanned scope changes may occur in the implementation or executing phase, conducting an annual quality audit contributes to discovering these changes, track them, and take corrective action if needed. In addition, by using the model of discovering potential changes in the project planning or execution phase, several healthy changes may arise, such as finding alternative approaches for implementing a process, removing redundant, or additional functions that may reduce project time, effort or cost. The proposed method categorizes the changes into five types: healthy changes, unhealthy changes, alternative changes, critical changes, and unplanned changes. Four types considered as planned changes, whereas the fifth type is unplanned changes which named scope creep, project management consider scope creep as one of the serious issues that cause project failure, it is recommended to estimate a maximum limit for scope creep and add it to project scope as a reserve, for instance, $5-10 \%$. Healthy changes are the changes that positively impact the project and considered as an opportunity. Unhealthy changes are changes that negatively impact the project in terms of cost and schedule baselines. Alternative changes that have no impact on the project and can be used as an alternative solution if needed. Critical changes are the changes that are not satisfying project goals and organizational objectives.

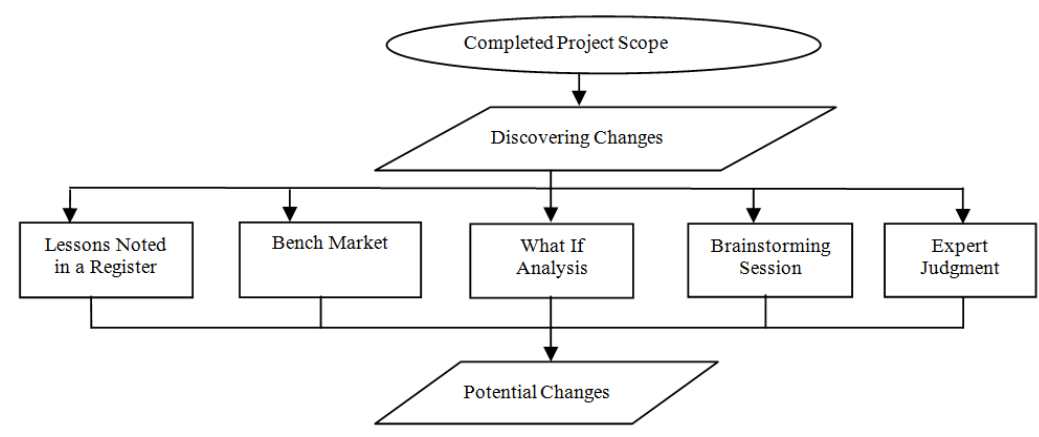

Figure 1. The proposed model to discover the changes in scope 
International Journal of Software Engineering \& Applications (IJSEA), Vol.12, No.2/3, May 2021

All the changes must be recorded in the changelog with its categorization, updated, and shared with all stakeholders, to easily track these changes and review them before making any changes or decisions. Assuming that a stakeholder makes a change request in the execution phase, the project manager should review the changelog first, if the change categorized as critical change, the project manager should not accept it unless it's categorized status updated, by raising another request to update the status and approved by senior managers or project sponsor. If the requested changes categorization shows unhealthy change, the project manager should provide alternative change if found, then suggest it to the requester to request it instead. However, the reassessment of the impact on project baselines (scope, schedule, and cost) must be implemented for all changes, unhealthy, alternative, and healthy categorization before making any change request.

Managing predefined project changes contribute to mitigating project risks, finding and tracking unplanned changes (scope creep) and prerecording some of the critical and unhealthy changes that negatively affect project baselines and unsatisfying project goals and organization objectives assist the project manager to identify potential risks, hence avoid them or plan for risk response. Dludhlu et al. [8] interviewed twenty four experts. According to Dludhlu et al. [8], "the risk was only identified when the project encountered a risk problem. Besides, in each period, the subject who manages the project will be responsible for managing the risk, most of the risk is not anticipated and not allocated when the project begins". The changelog is recommended as an electronic document that is easy to use, update, track, and share among the project management team and stakeholders. In addition, the change log may use as a knowledge reference for the organization as it contains all the changes on the project. According to Israeli and Gonen [7], the actual use of knowledge for project implementation is an indicator that leads to a stronger correlation between knowledge management and project success.

\section{VALIDATION}

In scientific research, validation is one of the significant ways to measure the effectiveness of proposed methods, models, or approaches, and evaluate the concepts of research papers. In this paper, the proposed method was validated using a survey approach. The aim of using this approach is to reach the required sample size and gather data from various geographic areas without worrying about time and cost constraints. The survey is used as a research tool to test the proposed method. Several issues are associated using a survey technique such as a large number of the participants did not fill the form properly and seriously and most of the provided information is ambiguous. A sample size of thirty participants is used to conclude the results. 
International Journal of Software Engineering \& Applications (IJSEA), Vol.12, No.2/3, May 2021

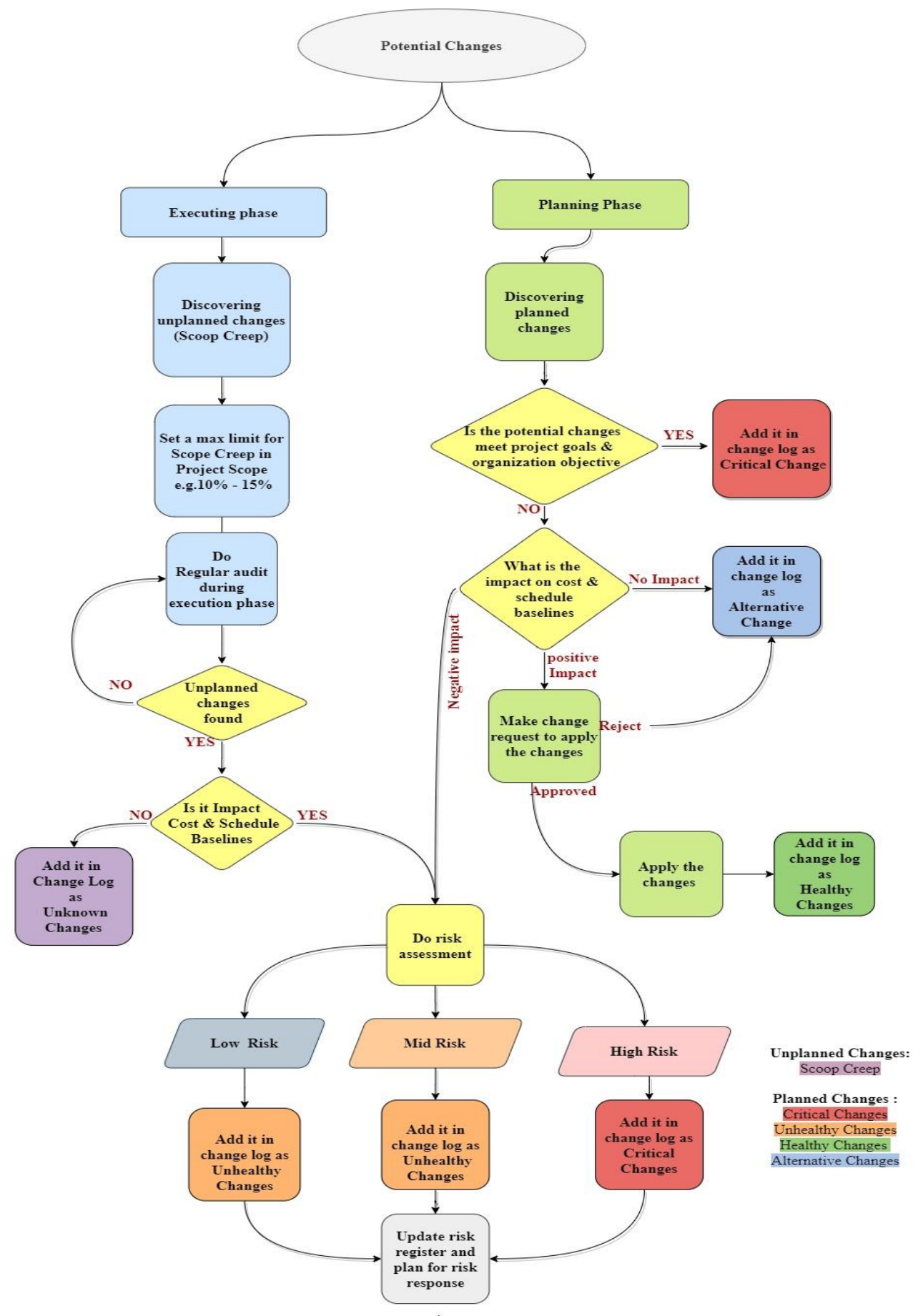

Figure 2. The Proposed Solution to Manage Predefined Project Scope Changes Method

The results of the conducted survey are displayed using a pie chart. The collected sample size encompasses 30 expertise participants working in different companies from various geographic areas. The sample's participants are holding different job professions like project manager, director, IT developer, IT manager, and programmers. We used an electronic form for the questionnaires; we shared the survey using various types of social media platforms such as WhatsApp, Telegram, Twitter, and Facebook. The participants used a likert scale to answer the electronic survey that is classified into 5 numbers. Number 1 indicates very low, number 2 refers 
International Journal of Software Engineering \& Applications (IJSEA), Vol.12, No.2/3, May 2021

to low, number 3 points to average, number 4 means high, and number 5 determines very high. The survey contains 27 questions that are divided into four main goals.

- Goal 1 aims to ensure that the proposed method is efficient and applicable to projects.

- Goal 2 aims to validate the advantages of predefining planned scope changes in the planning phase.

- Goal 3 aims to validate the advantages of predefining and tracking unplanned scope changes (Scope Creep) in the executing phase.

- Goal 4 aims to identify the relation between the proposed method and the Change Management System and evaluate the possibility of the integration.

\subsection{Cumulative Analysis of Goal 1}

The results of the cumulative analysis of goal 1 are shown in figure 3. It is depicted from figure 3 that $26 \%$ of participants are strongly agreed that the proposed method is applicable and efficient, whereas $35 \%$ are agreed, $27 \%$ are neither agreed nor disagreed, $9 \%$ have disagreed, and $1 \%$ of the respondents strongly disagreed.

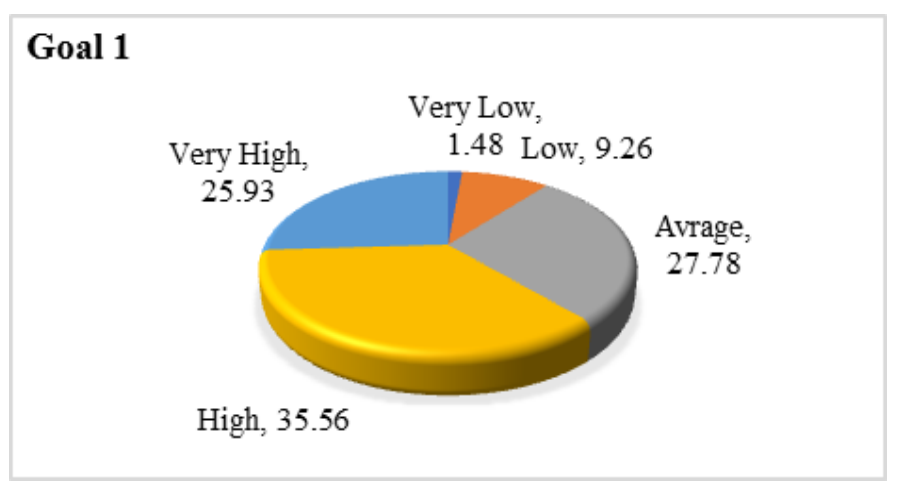

Figure 3. Cumulative Analysis of Goal 1

\subsection{Cumulative Analysis of Goal 2}

The results of the cumulative analysis of goal 2 are displayed in figure 4 . Figure 4 displays that $36 \%$ of participants are strongly agreed with the advantages of implementing the proposed method in the planning phase, whereas 38\% are agreed, $21 \%$ are neither agreed nor disagreed, $4 \%$ have disagreed, and $1 \%$ of the participants are strongly disagreed.

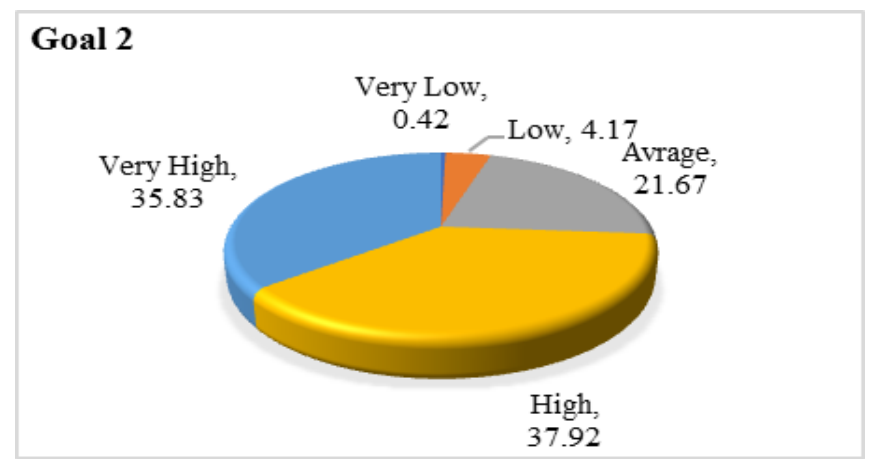

Figure 4. Cumulative Analysis of Goal 2 


\subsection{Cumulative Analysis of Goal 3}

The results of the cumulative analysis of goal 3 are presented in figure 5. It is inferred from figure 5 that $28 \%$ of participants are strongly agreed with the advantages of implementing the proposed method in the executing phase, whereas $35 \%$ are agreed, and $31 \%$ are neither agreed nor disagreed, $5 \%$ disagreed, and $1 \%$ strongly disagreed.

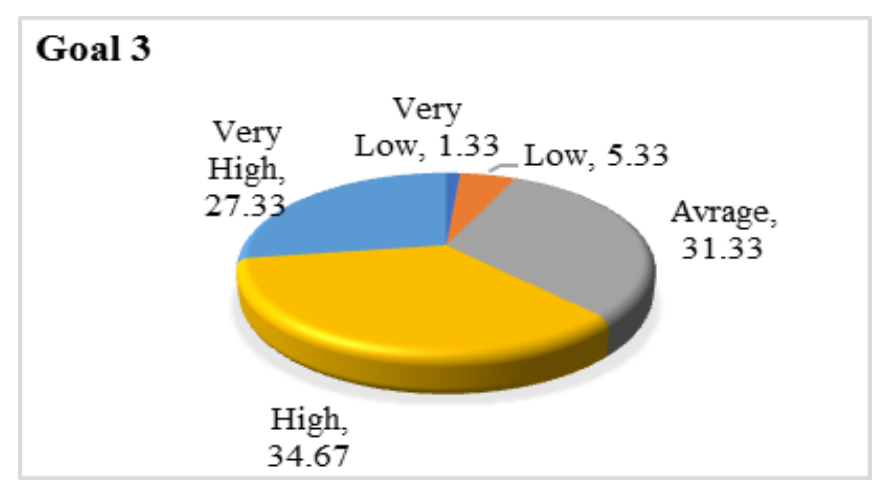

Figure 5. Cumulative Analysis of Goal 3

\subsection{Cumulative Analysis of Goal 4}

The results of the cumulative analysis of goal 4 are shown in figure 6 . Figure 6 shows that $17 \%$ of the participants are strongly agreed with the advantages of integrating the proposed method with the change management system, whereas $35 \%$ are agreed, and $31 \%$ are neither agreed nor disagreed, $5 \%$ disagreed, and $1 \%$ strongly disagreed.

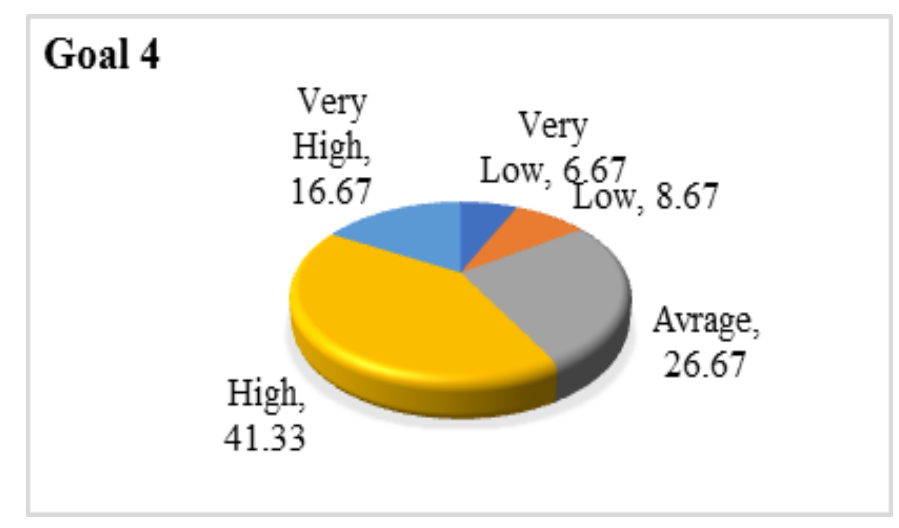

Figure 6. Cumulative Analysis of Goal 4

\subsection{Final Cumulative Analysis of Four Goals}

The final cumulative analysis of four goals is displayed in figure 7. Figure 7 indicates that $27 \%$ of the respondents are strongly agreed, and $37 \%$ are agreed, whereas $26 \%$ are neither agreed nor disagreed, $6 \%$ disagreed, and $2 \%$ strongly disagreed. 
International Journal of Software Engineering \& Applications (IJSEA), Vol.12, No.2/3, May 2021

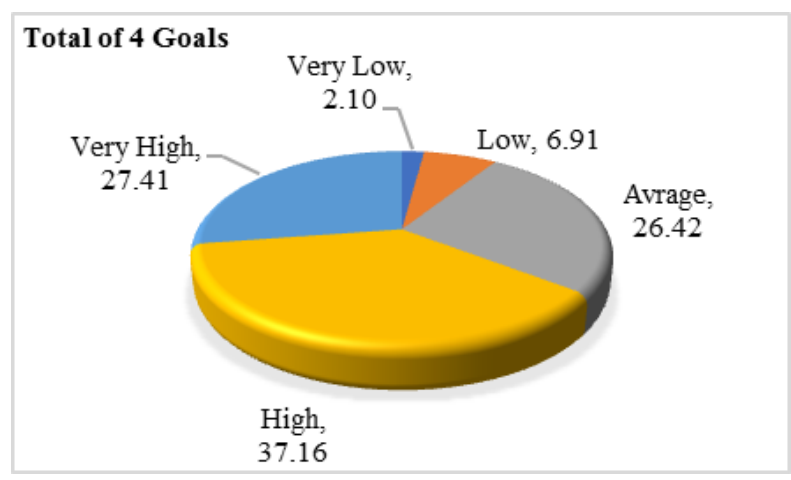

Figure 7. Final Cumulative Analysis of 4 Goals

\section{Conclusions}

In this research, the predefined project scope changes method proposed to overcome project failure as a result of poor project scope definition and unfavourable changes that occurred in project scope either during the planning phase or executing phase. In this research there a list of tools and techniques are suggested in discovering potential scope changes model. We defined potential scope changes into two main classifications: the first one is planned scope changes include critical changes, healthy changes, unhealthy changes, and alternative changes. The second one is unplanned scope changes (scope creep). In this paper, an efficient mechanism proposed to deal with the potential changes or detect scope creep to mitigate project risks and increase the scope change awareness. In addition, the proposed method may prevent the project from exceeding the project budget and time waste consequences implementing unfavourable scope changes. The proposed method may associate with a change management system by using an electronic integrated "change log" document to control of project scope effectively. Furthermore, the result of this study may be used in future studies and applied in real-life projects to assist project managers in mitigating project risks.

\section{REFERENCES}

[1] Sharma, R., Sohi, A., Hertogh, M. and Deketh, J., (2017) "Controlling the uncontrolled by noticing the unnoticed", Int. Conf. Computer Sciences and Information Technologies (CSIT), Ukraine, pp106-112.

[2] Adam, A. and Danaparamita, M. (2016) "Understanding The Influence of Poor Scope Management Affecting the Successful of an IT Project", Int. Conf. Information Management and Technology (ICIMTech), Ukraine, pp124-129.

[3] Komal, B., JanJua, U., and Madni, T., (2019) "Identification of scope creep factors and their impact on software project success", Int. Conf. Computer and Information Sciences (ICCIS), Saudi Arabia, pp15 .

[4] Valdés-Souto, F., (2019) "Earned Scope Management: Scope Performance Evaluation for Software Projects Considering People and Effort as Resources", Int. Conf. Software Engineering Research and Innovation (CONISOFT), Mexico, pp213-222.

[5] Hassan, I., Ahmad, N., and Zuhaira, B., (2017) "Calculating completeness of software project scope definition", J Info and Software Tech, Vol. 94, pp208-233.

[6] Xiong, G., Zhao, A., Nyberg, T. and Xiong, G.A., (2016) "Change Management on Improvement Project for Success", Int. Conf. Service Operations and Logistics, and Informatics (SOLI), China, pp53-59.

[7] Israeli, U., and Gonen, A., (2018) "Project Success as a Function of Organizational Knowledge Management", Int. Conf. Industrial Engineering and Engineering Management (IEEM), Thailand, pp356-360. 
International Journal of Software Engineering \& Applications (IJSEA), Vol.12, No.2/3, May 2021

[8] Dludhlu, N., Pretorius, J., and Wyngaard, C., (2017) "Risk Evaluation in Project Management Implementation: The Case of Infrastructural Development Projects", Int. Conf. Industrial Engineering and Engineering Management (IEEM), Singapore, pp1743-1747.

[9] Battistello, L., Kristjansdottir, K. and Hvam, L., (2018) "Scoping a PIM System: A Supporting Framework", Int. Conf. Industrial Engineering and Engineering Management (IEEM), Thailand, pp1831- 1835.

[10] Pollack, J., (2016) "The Need for Integration Between Organizational Project Management and Change Management", Int. Conf. Industrial Engineering and Engineering Management (IEEM), Indonesia, pp1245-1249.

[11] Komal, B., Janjua, UI., Anwar, F., Madni, M., Cheema, MF., Malik, MN., \& Shahid, AR., (2020) "The Impact of Scope Creep on Project Success: An Empirical Investigation”, IEEE Access, Vol. 8, pp125755-125775.

[12] Tariq, S., Ahmad, N., Ashraf, MU., Alghamdi, AM., \& Alfakeeh, AS., (2020) "Measuring the Impact of Scope Changes on Project Plan using EVM", IEEE Access, Vol. 8, pp154589-154613.

[13] Soltan, S. \& Ashrafi, M., (2020) "Predicting project duration and cost and selecting the best action plan using statistical methods for earned value management", J. Project Manage., Vol. 5, pp157-166.

[14] Miguel, A., Madria, W., \& Polancos, R., (2019) "Project Management Model: Integrating Earned Schedule, Quality, and Risk in Earned Value Management", Int. Conf. Industrial Engr. and App. (ICIEA), Japan, pp622-628.

[15] Pressman, RS, (2015) Software Engineering, McGraw-Hill Publisher.

[16] Salo, O. \& Abrahamsson P., (2008) "Agile methods in European embedded software development organisations: a survey on the actual use and usefulness of Extreme Programming and Scrum", J IET SW, Vol. 2, pp58-64.

\section{AUTHORS}

Mr. Theyab Althiyabi is a master student in the Department of IT, King Abdulaziz University, Jeddah, Saudi Arabia.

Prof. Dr. Rizwan Qureshi received his Ph.D. Degree in Computer Sciences from National College of Business Administration \& Economics, Pakistan in 2009. He is currently working as a full professor in the Department of IT, King Abdulaziz University, Jeddah, Saudi Arabia. This author is the best researcher awardees from the Department of Information Technology, King Abdulaziz University in 2013 and 2016.

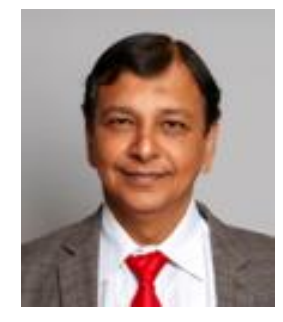

